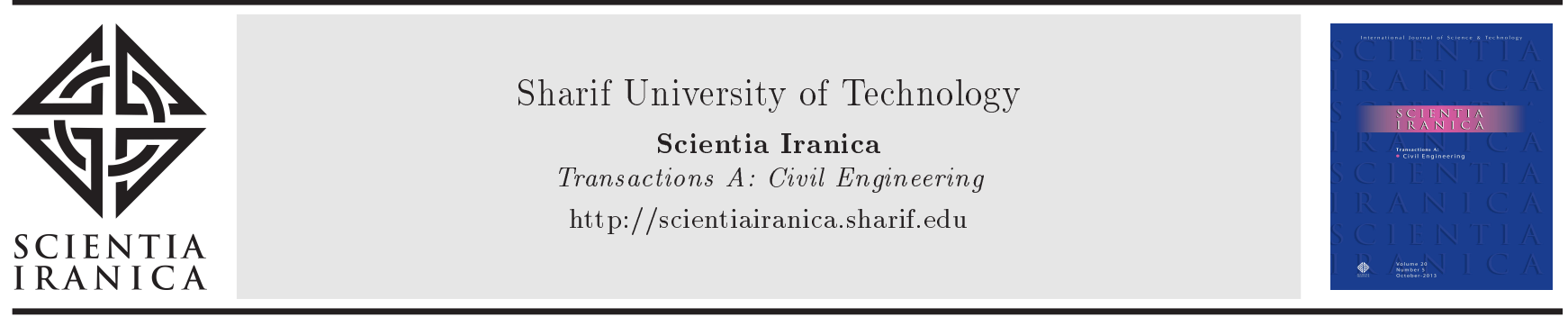

\title{
Prediction of meteorological and hydrological phenomena in different climatic scenarios in the Karkheh watershed (southwest of Iran)
}

\author{
A. Adib*, S.B. Mirsalari, and S.M. Ashrafi \\ Department of Civil Engineering, Faculty of Engineering, Shahid Chamran University of Ahvaz, Ahvaz, Iran.
}

Received 2 May 2018; received in revised form 16 June 2018; accepted 6 August 2018

\author{
KEYWORDS \\ SDSM model; \\ IHACRES model; \\ GCMs models; \\ The MK trend test; \\ The TSA estimator.
}

\begin{abstract}
This research evaluates the effects of climate change on future temperature, precipitation, and flow discharge in the Karkheh watershed (a watershed in southwest of Iran). For this purpose, General Circulation Models (GCMs) and the non-parametric Mann-Kendall (MK) trend test are utilized. Considered hydrometric station is the Jelogir station at the upstream of the Karkheh Dam. The base time period is 1971-2014 and the future time period is 2030-2073 for the prediction of meteorological and hydrometric phenomena in the Jelogir station. For GCM model, the Canadian Climate Change Scenarios Network (CCCSN) database represents data of HadCM3 model for A2 and B2 scenarios. To investigate the watershed, this research applies Statistical DownScaliny Model (SDSM) downscaling model and introduces the predicted precipitation and temperature of the future time periods to IHACRES (Identification of unit Hydrographs And Component flows from Rainfall, Evapotranspiration and Streamflow) model for flow discharge prediction. In addition, the non-parametric MK trend test and the Theil-Sen Approach (TSA) estimator distinguish the trend of observed and predicted data. Results of scenarios A2 and B2 are not that much different. Different climatic scenarios show that temperature increases and precipitation and flow discharge decrease. Moreover, MK test and TSA estimator show that the slope of their variations will slow down in the future, and most of changes are associated with and observed in the winter and spring.
\end{abstract}

(C) 2020 Sharif University of Technology. All rights reserved.

\section{Introduction}

Global warming and climate change are basic problems that human societies face today. In the Middle East, these phenomena have become unrelenting challenges that can cause wars and huge immigrations among different countries and regions. Natural secondary

\footnotetext{
*. Corresponding author.

E-mail addresses: arashadib@scu.ac.ir (A. Adib);

sbmirsalari@yahoo.com (S.B. Mirsalari); ashrafi@scu.ac.ir (S.M. Ashrafi)
}

doi: $10.24200 /$ sci.2018.50953.1934 effects of these phenomena include drying wetlands and generation of dust storms. Human activities such as construction of large dams worsen secondary effects of climate change. The Karkheh Dam is the largest earth dam in Iran. Iranian government constructed this dam in 1996. The occurrence of extreme droughts in recent years, the environmental effects of the Karkheh Dam, and climate change dried the Hoor-Al-Azim wetland, which is now a major source of dust storms.

Prediction of precipitation, temperature, and flow discharge at the upstream of the Karkheh Dam is a necessary task for evaluating the occurrence and severity of droughts. This forecast can help designers and managers with correct planning and water 
resources management (as wetlands management). The selection of appropriate methods and climatic scenarios is very important for managers and designers. For this reason, this research considers different methods and climatic scenarios.

The Mann-Kendal (MK) test [1,2] and the TheilSen Approach (TSA) [3,4] (as nonparametric methods) have been used in this study. The nonparametric methods are distribution-free, robust against outliers, and enjoy greater capability for non-normally distributed data, according to Yue et al. [5].

Taxak et al. [6] showed the decreasing trend of annual rainfall from 1949 to 2012 in Wainganga basin, central India. Kumar and Jain [7] showed the decreasing trend of annual rainfall from 1951 to 2004 in most watersheds of India. Subash et al. [8] stated that rainfall experienced a significant increasing trend during July, August, and September in some watersheds of India. Sayemuzzaman and Jha [9] showed that rainfall experienced an increasing trend in the winter and a decreasing trend in the fall in the state of North Carolina, U.S.A. from 1950 to 2009. Tekleab et al. [10] demonstrated that precipitation did not experience any significant trend and, also, seasonal and annual temperatures had a significant increasing trend within the Abay/Upper Blue Nile basin in Ethiopia. Addisu et al. [11] stated that mean, maximum and minimum temperatures had an increasing trend and rainfall had a decreasing trend in Lake Tana sub-basin, Ethiopia. Beyene [12] stated that monthly rainfall experienced a decreasing trend from May to July during 1995 to 2014 in Mekelle city of Ethiopia. Croitoru et al. [13] stated that annual and summer reference evapotranspiration showed an increasing trend, and the fall reference evapotranspiration experienced a decreasing trend in Romania. De la Casa and Nasello [14] evaluated the number of rainy days and precipitation trends from 1960 to 2010 in Córdoba Province of Argentina and found a relationship between them and the effect of cosmic rays. Adib et al. [15] showed the increasing trend of temperature and the decreasing trend of rainfall and flow discharge during 1970-2009 in the Kasilian watershed of Iran. Somee et al. [16] showed that the annual rainfall and winter and spring rainfalls underwent a decrease during 1967-2006 in most parts of Iran. Tabari et al. [17] stated that mean, maximum and minimum temperatures experienced an increasing trend in south, west, and southwest of Iran. Abghari et al. [18] showed the decreasing trend of annual flow discharge during 1969-2009 in mountainous western regions of Iran. Khalili et al. [19] indicated that the annual and winter rainfalls experienced a decreasing trend during 1961-2010 in more than half of Iran (especially, south of Iran). Zamani et al. [20] showed that monthly, seasonal, and annual flow discharges demonstrated a decreasing trend during 1974-2011 in the Karkheh watershed of Iran. Ay and Kisi [21] pointed out the increasing trend of monthly precipitation in several provinces of Turkey. Xu et al. [22] found the increasing trend of rainfall and flow discharge in the south of China and the decreasing trend of precipitation and flow discharge in the north of China during 1951-2000. Caloiero [23] stated that minimum and maximum temperatures experienced an increasing trend in New Zealand since 1951. These researchers have utilized MK and TSA methods for trend analysis of the meteorological and hydrological phenomena.

Further, Wang and Lau [24] applied 16 Coupled General Circulation Models (CGCMs) and showed growing precipitation in tropical oceans and low precipitation in tropical lands and cloud cover in the twentieth century; results of CGCMs are consistent with observations. DeGaetano and Castellano [25] applied the downscaling method and demonstrated that precipitation would increase from 2010 to 2100 in New York state, U.S.A. Hashmi et al. [26] utilized GCMs, Statistical DownScaling Model (SDSM), Long Ashton Research Station Weather Generator (LARSWG), and Generalized Extreme Value (GEV) distribution for simulating rainfall intensity based on different return periods in the Clutha watershed of New Zealand. Gulacha and Mulungu [27] utilized SDSM and A2 and B2 scenarios in Wami-Ruvu River Basin of Tanzania, and showed that rainfall and maximum temperature would increase and minimum temperature would decrease. Lima et al. [28] used GCMs and the traditional GEV distribution for generating Intensity-DurationFrequency (IDF) curves in Korea, and showed that the intensity of rainfalls with short durations and long return periods may increase in the future. Agilan and Umamahesh [29] applied GCMs and ' $K$ ' Nearest Neighbor (KNN) weather generator downscaling method in the Hyderabad city of India for generating IDF curves, and showed that the intensity of rainfalls would increase in the future. Mailhot et al. [30] applied the Canadian Regional Climate Model (CRCM) in Southern Quebec of Canada for generating IDF curves in the future, and illustrated that the intensity of rainfalls would increase. Alam and Elshorbagy [31] utilized GCMs, KNN, GEV distribution and Representative Concentration Pathways (RCP) for the generation of IDF curves in the Saskatoon city of Canada, and found that the main source of uncertainty was a type of used GCMs and RCPs. Simonovic et al. [32] updated IDF curves in Canada by downscaling method and decision support system. Khan et al. [33] compared uncertainty degrees of SDSM, LARS-WG, and Artificial Neural Network (ANN) for the downscaling of daily precipitation and minimum and maximum temperatures. SDSM achieved the most certain results during 1961-2000 in Canada. Kuo et al. [34] utilized RCM and the Fifth Generation Pennsylvania State 
University/National Center for Atmospheric Research Mesoscale Model (MM5) for the generation of IDF in Central Alberta of Canada. Pour et al. [35] developed a Support Vector Machine (SVM) based Model Output Statistics (MOS) for downscaling. They applied the aforementioned method, GCM, and Coupled Model Intercomparison Project, phase 5 (CMIP5) and derived monthly rainfall data using Global Precipitation Climatological Center (GPCC) to predict the annual and seasonal rainfalls in Bangladesh. They showed that the annual rainfall would increase in this country. Sehgal et al. [36] considered a wavelet-based multi-resolution modeling approach to downscaling GCM variables and monthly rainfall in the Krishna watershed of India from 1995 to 2005 and forecast period from 2006 to 2035. The observed data were prepared using India meteorological department database. In addition, for clustering climatic variables, a novel Multi-scale Wavelet Entropy (MWE) was utilized, the results of which were more accurate than those of Multiple Linear Regression (MLR) and ANN. Hertig and Tramblay [37] applied Standardized Precipitation Index (SPI) and a downscaling method based on geopotential heights and relative humidity in the Mediterranean region. They used the coupled Max Planck Institute Earth System Model (MPI-ESM-LR) and RCP 8.5 scenario, and showed that the severity and occurrence of droughts would increase from 2070 to 2100. Osman and Abdellatif [38] combined three models (SDSM, MLR, and Generalized Linear Model (GLM)) for the downscaling of rainfall characteristics in North-western England. They observed that the results of this combined model were much more accurate than those of traditional ANN and Simple Average Method (SAM). Sinha et al. [39] utilized the Coupled Model Inter-comparison Project, phase 5 (CMIP5), a downscaling model based on self-organized maps and scenarios RCP2.6, RCP4.5, and RCP8.5 in south Florida, U.S.A. during 1976-2005. They predicted that the average length of seasonal drought periods would increase in the near future (2021-2050) and distant future (2071-2100). Sachindra et al. [40] used four methods for downscaling Genetic Programming (GP), ANNs, SVM, and Relevance Vector Machine (RVM) in the Australian State of Victoria during 1950 to 2014. They reported that RVM is the most suitable method for drought analysis, and RVM and ANNs are the most suitable methods for performing flood analysis. Sa'adi et al. [41] utilized 20 GCMs of CMIP5 and four scenarios RCP2.6, RCP4.5, RCP6.0, and RCP8.5. They used two downscaling methods, Random Forest (RF) and SVM, in Sarawak of Borneo Island (in Malaysia). They observed that results of SVM were more accurate than those of $\mathrm{RF}$, and mean annual rainfall would increase in the future. Pour et al. [42] combined RF and SVM methods for downscaling daily rainfall on the eastern coast of peninsular Malaysia. They concluded that results of this hybrid model were more accurate than those of SVM or RF methods. Adib and Gafari rad [43] used the HadCM3 (Hadley Centre Coupled Model, version 3 ) and A1B, B1, and A2 scenarios in the Baghmalek climatic station of Iran. The base period spans the years between 1974 and 2013 and the forecast period between 2021 and 2050. They utilized radial base function ANN for downscaling, and concluded that rainfall intensity would increase in return periods less than 2.33 years, while it would decrease in return periods more than 2.33 years. Sahraei et al. [44] predicted the daily river flow of the Kashkan watershed using Least Square Support Vector Regression (LSSVR) and Regression Tree (RT) methods. They observed that results of LSSVR method were more accurate than those of RT method. These researchers have applied GCMs and different downscaling methods for predicting climatic phenomena (precipitation, temperature, etc.) in the future. This research takes the following steps:

1. Preparation of daily precipitation, temperature, and flow discharge data of the Jelogir station in the base time period (1971-2014);

2. Prediction of daily precipitation and temperature by GCM model. The used GCM model is HadCM3 model. This model predicts these meteorological phenomena based on scenarios A2 and B2 in the future time period (2030-2073);

3. Downscaling of the predicted daily precipitation and temperature by GCM model. For this purpose, SDSM downscaling model has been used;

4. Simulation of flow discharge by IHACRES model. The parameters of IHACRES model are calibrated using the observed flow discharge in the base time period (1971-2014);

5. Prediction of daily flow discharge using the predicted daily precipitation and temperature by SDSM downscaling model and calibrated IHACRES model in the future time period (2030-2073);

6. Determination of monthly and seasonal precipitation, temperature, and flow discharge trend in the base time period (1971-2014) and the future time period (2030-2073). For this purpose, MK trend test and TSA estimator are used;

7. Comparison between trends of predicted monthly precipitation, temperature, and flow discharge in the future time period (2030-2073) by different scenarios and the trend of observed monthly precipitation, temperature, and flow discharge in the base time period (1971-2014). 


\section{The Karkheh watershed and Jelogir station}

The Karkheh River (the third largest river in Iran) is located in southwest of Iran. The source of this river is the Zagros Mountains, and the river flows into Hooral-Azim wetland on the Iran-Iraq border. The area of its watershed $\left(46^{\circ} 6^{\prime}-49^{\circ} 10^{\prime} \mathrm{E}\right.$ and $\left.30^{\circ} 58^{\prime}-35^{\circ} \mathrm{N}\right)$ is characterized by $51481.9 \mathrm{~km}^{2}$. Minimum, average, and maximum heights of this watershed are $3 \mathrm{~m}, 1320 \mathrm{~m}$, $3645 \mathrm{~m}$, respectively. Minimum, average, and maximum annual temperatures are $-1,15.3$, and $25.8^{\circ} \mathrm{C}$, respectively. Minimum, average, and maximum annual precipitations (rainfalls occur in winter) are 205, 477, and $1000 \mathrm{~mm}$, respectively. The average annual height of potential evaporation is $2290 \mathrm{~mm}$. The Jelogir station (constructed in 1957) is at the upstream of the Karkheh Dam (dam does not regulate flow discharge of this station). This station is situated at $47^{\circ} 50^{\prime} 12^{\prime \prime} \mathrm{E}$ and $32^{\circ} 56^{\prime} 34^{\prime \prime} \mathrm{N}$ and is characterized by $385 \mathrm{~m}$ in height. The area and mean annual flow discharge of this station are $39940 \mathrm{~km}^{2}$ and 167 CMS, respectively. The map of this watershed is shown in Figure 1.

\section{Components of research}

\subsection{The MK trend test and TSA estimator}

The MK test is the rank-based nonparametric test $[1,2]$. Test statistic $S$ is:

$$
S=\sum_{i=1}^{n-1} \sum_{j=i+1}^{n} \operatorname{sgn}\left(x_{j}-x_{i}\right)
$$

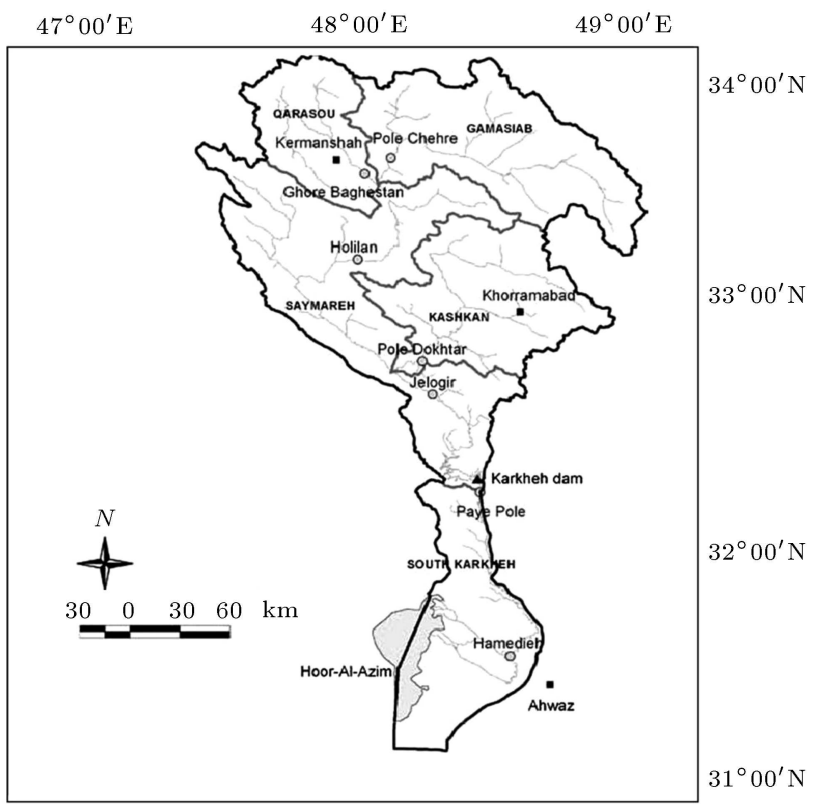

Figure 1. The Karkheh watershed and Jelogir station [45]. where $x_{i}$ and $x_{j}$ are the sequential data values, $n$ is the number of data, and sgn is a function:

$$
\operatorname{sgn}(y)=\left\{\begin{array}{ll}
1 & \text { if }(y>0) \\
0 & \text { if }(y=0) \\
-1 & \text { if }(y<0)
\end{array}\right\} .
$$

Theil-Sen's estimator has been used to estimate the slope of $N$ pairs of data points [3,4] and calculate it as follows:

$$
Q i=\left(x_{j}-x_{k}\right) /(j-k) \quad \text { for } \quad i=1 \cdots N
$$

where $x_{j}$ and $x_{k}$ are data values at times $j$ and $k(j>k)$. The median of these $N$ values of $Q_{i}$ is Sen's estimator of slope.

\subsection{The HadCM3 and the Special Report on Emissions Scenarios (SRES)}

The HadCM3 is a coupled atmosphere-ocean general circulation model. The Hadley Centre in the United Kingdom developed this model which has two components: the atmospheric model HadAM3 (Hadley Centre Atmospheric Model Version 3) and the ocean model HadOM3 (Hadley Centre Ocean Model Version 3). The HadOM3 is characterized by a sea ice model. Moreover, this model does not need flux adjustment for improving simulation. For simulation, this model assumes that the number of days in a year is 360 days (each month is 30 days). The advantages of this model are the high resolution of HadOM3 and good coordination between HadOM3 and HadAM3 [46-48].

The Intergovernmental Panel on Climate Change (IPCC) published a report (SRES) in 2000. This report described scenarios of greenhouse gas emissions. These scenarios can be used for predicting climate changes in the future. Moreover, IPCC published the IPCC Third Assessment Report (TAR) in 2001 and the IPCC Fourth Assessment Report (AR4) in 2007. TAR and AR4 described four scenarios (A1, A2, B1, and B2). In this research, two scenarios have been considered: A2 and B2.

The A2 scenario family predicts a very heterogeneous world. Characteristics of this scenario include self-reliance and preservation of local identities. The population will increase continuously. Economic development is not global and is different in developed and developing countries. Per capita economic growth and technological change are more fragmented and slower than those in other scenarios [49].

The B2 scenario family predicts a world that considers local solutions for economic, social, and environmental sustainability. This scenario considers a continuously growing global population at a rate lower than that in A2 and intermediate levels of economic development. Moreover, the purpose of this scenario is environmental protection and social equity; it focuses 
on local and regional levels [49]. The characteristics of the two scenarios are shown in Table 1.

\subsection{IHACRES model}

This research uses a rainfall-runoff model called IHACRES. Jakeman et al. [50] introduced the principles of this model. IHACRES is characterized by eight parameters and two components (linear and non-linear components). These parameters are given below:

In nonlinear component:

$\begin{array}{ll}c & \text { Mass balance term } \\ f & \text { Temperature dependence of drying } \\ & \text { rate } \\ t_{r e f} & \text { Reference temperature } \\ l & \text { Moisture threshold for producing flow } \\ p & \text { Power on soil moisture } \\ \tau_{w} & \text { Drying rate at a reference temperature }\end{array}$

In linear component:

$\alpha_{q}, \alpha_{s} \quad$ Recession rate of quick and slow flows

$\beta_{q}, \beta_{s} \quad$ Peak responses of quick and slow flows

$\tau_{q} \quad$ Time constant of quick flows $\left(=-\Delta / \ln \left(-\alpha_{q}\right)\right)$

$\tau_{s} \quad$ Time constant of slow flows $\left(=-\Delta / \ln \left(-\alpha_{s}\right)\right)$

$v_{q} \quad$ Volume proportion of quick flows $\left(=\beta_{q} /\left(1+\alpha_{q}\right)\right)$

$v_{s} \quad$ Volume proportion of slow flows $\left(=\beta_{s} /\left(1+\alpha_{s}\right)\right)$

\subsection{Input data}

The daily data used in this study are associated with Jelogir station. The sources of these data are databases of the Iranian Ministry of Energy and the Iran Meteorological Organization. No data were missing in the base time period (1971-2014). Monthly and annual flow discharge and temperature are equal to the average flow discharge and temperature in the same month and year, and the monthly and annual precipitations are equal to the sum of precipitation in the same month and year.

The run test showed that data (annual, seasonal, and monthly data) are homogenous $(|Z|>1.96$ in Table 2).

Pettitt's test [51] illustrates that data (annual, seasonal, and monthly data) do not have any change points $(|Z|<1.96$ in Table 3$)$.

\subsection{Performance criteria}

Used performance criteria are given below:

Root Mean Square Error (RMSE):

$$
R M S E=\sqrt{\frac{1}{n} \sum_{i=1}^{n}\left(X_{c i}-X_{o i}\right)^{2}}
$$

where $X_{c}$ is the calculated value of parameter, $X_{o}$ is the observed value of parameter, and $n$ is the number of observations.

Normalized Root Mean Square Error (NRMSE):

$$
N R M S E=\frac{R M S E}{X_{o \max }-X_{o \min }} .
$$

\begin{tabular}{|c|c|c|c|c|c|c|c|}
\hline \multirow{2}{*}{ Characteristics } & \multirow{2}{*}{1990} & \multicolumn{3}{|c|}{ A2 } & \multicolumn{3}{|c|}{ B2 } \\
\hline & & 2020 & 2050 & 2100 & 2020 & 2050 & 2100 \\
\hline Population (billion) & 5.3 & 8.2 & 11.3 & 15.1 & 7.6 & 9.3 & 10.4 \\
\hline World GDP $\left(10^{12} 1990 \mathrm{US} \$ / \mathrm{yr}\right)$ & 21 & 41 & 82 & 243 & 51 & 110 & 235 \\
\hline $\begin{array}{l}\text { Per capita income ratio: developed countries and } \\
\text { economies in transition to developing Countries }\end{array}$ & 16.1 & 9.4 & 6.6 & 4.2 & 7.7 & 4 & 3 \\
\hline Share of coal in primary energy $(\%)$ & 24 & 22 & 30 & 53 & 17 & 10 & 22 \\
\hline Share of zero carbon in primary energy $(\%)$ & 18 & 8 & 18 & 28 & 18 & 30 & 49 \\
\hline Carbon dioxide (GtC/yr) & 7.1 & 12.2 & 17.4 & 29.1 & 9 & 11 & 13.3 \\
\hline Sulfur dioxide (MtS/yr) & 70.9 & 100 & 105 & 60 & 61 & 56 & 48 \\
\hline Methane (MtCH4/yr) & 310 & 424 & 598 & 889 & 384 & 505 & 597 \\
\hline $\mathrm{NO}_{x}(\mathrm{MtN} / \mathrm{yr})$ & 30.9 & 50 & 71 & 109 & 43 & 55 & 61 \\
\hline $\mathrm{CO}(\mathrm{MtCO} / \mathrm{yr})$ & 879 & 1075 & 1428 & 2326 & 1022 & 1319 & 2002 \\
\hline
\end{tabular}

Table 1. The characteristics of two scenarios A2 and B2 [49]. 
Table 2. The results of the run test.

\begin{tabular}{lccc}
\hline \multirow{2}{*}{ Month-season } & \multicolumn{3}{c}{$|\boldsymbol{Z}|$} \\
\cline { 2 - 4 } & Precipitation Temperat ure & $\begin{array}{c}\text { Flow } \\
\text { discharge }\end{array}$ \\
\hline Jan & 9.62 & 3.58 & 4.91 \\
Feb & 5.35 & 3.66 & 6.09 \\
Mar & 13.58 & 13.08 & 7.01 \\
Apr & 16.57 & 4.74 & 7.67 \\
May & 16.17 & 10.08 & 4.67 \\
Jun & 6.98 & 5.84 & 4.45 \\
Jul & 4.44 & 14.15 & 6.92 \\
Aug & 9.75 & 16.68 & 7.54 \\
Sep & 15.97 & 12.56 & 8.49 \\
Oct & 14.03 & 4.86 & 4.62 \\
Nov & 9.75 & 5.42 & 5.22 \\
Dec & 11.37 & 6.43 & 6.5 \\
Winter & 12.37 & 4.8 & 8.47 \\
Spring & 15.04 & 8.38 & 7.42 \\
Summer & 7.081 & 7.41 & 3.81 \\
Autumn & 14.78 & 11.67 & 8.87 \\
Annual & 5.5 & 13.09 & 4.88 \\
\hline
\end{tabular}

Table 3. The results of Pettitt's test.

\begin{tabular}{lccc}
\hline \multirow{2}{*}{ Month-season } & \multicolumn{3}{c}{$|\boldsymbol{Z}|$} \\
\cline { 2 - 4 } & Precipitation Temperat ure & $\begin{array}{c}\text { Flow } \\
\text { discharge }\end{array}$ \\
\hline Jan & 0.3 & 0.95 & 0.5 \\
Feb & 0.75 & 0.65 & 1.66 \\
Mar & 0.5 & 0.86 & 1.03 \\
Apr & 0.42 & 0.9 & 0.85 \\
May & 0.63 & 0.77 & 1.34 \\
Jun & 0.45 & 0.89 & 0.91 \\
Jul & 0.04 & 0.99 & 0.08 \\
Aug & 0.64 & 0.76 & 1.36 \\
Sep & 0.57 & 0.81 & 1.21 \\
Oct & 0.66 & 0.74 & 1.42 \\
Nov & 0.44 & 0.89 & 0.91 \\
Dec & 0.18 & 0.98 & 0.36 \\
Winter & 0.16 & 0.98 & 0.32 \\
Spring & 0.78 & 0.62 & 1.76 \\
Summer & 0.55 & 0.83 & 1.14 \\
Autumn & 0.4 & 0.91 & 0.81 \\
Annual & 0.42 & 0.9 & 0.86 \\
\hline
\end{tabular}

Correlation coefficient $\left(R^{2}\right)$ :

$$
R^{2}=\frac{\sum_{i=1}^{n}\left(X_{c i}-\overline{X_{c}}\right)\left(X_{o i}-\overline{X_{o}}\right)}{\sqrt{\sum_{i=1}^{n}\left(X_{c i}-\overline{X_{c}}\right)^{2}\left(X_{o i}-\overline{X_{o}}\right)^{2}}}
$$

The values of RMSE and NRMSE should be close to zero and $R^{2}$ should be close to one.

\subsection{The objectives and novelty of research}

The objectives of this research are given below:

1. Determination of the trend of observed precipitation, temperature, and flow discharge by the MK test and TSA estimator. For this purpose, the 43year time period, 1971-2014, has been considered and about daily precipitation of 48000 , temperature, and flow discharge data for trend analysis have been applied. The MK test and TSA estimator can help distinguish the direction of trend, significance or insignificance of trend, its confidence level, and the slope value of trend line;

2. Prediction of monthly and seasonal precipitations and temperature by GCMs and SDSM downscaling model from 2030 to 2073 and based on scenarios $\mathrm{A} 2$ and B2. The purpose of this prediction is to identify future weather conditions in terms of economic development or environmental protection. Moreover, the results of these two scenarios are compared with those of the continuation of the existing climatic conditions (determined by the MK trend test and TSA estimator);

3. Prediction of monthly and seasonal flow discharge based on the predicted precipitation and temperature and by IHACRES model at the interval of 2030 to 2073 and based on scenarios A2 and B2. Moreover, the results of these two scenarios will be compared with those of the continuation of the existing hydrological conditions (determined by the MK trend test and TSA estimator);

4. Determination of the trend of predicted monthly and seasonal precipitations, temperature, and flow discharge by the MK trend test and TSA estimator and the comparison of these trends and observed data;

5. Making a comparison between observed and different predicted data and results of applied methods such as trend of observed and predicted data is the main purpose of this research. This comparison can illustrate the importance of economic development or environmental protection in the Karkheh watershed. The proposed method can be a guide for evaluating future warming or cooling and occurrence or non-occurrence of more severe hydrological and climatic droughts in different regions around the world. 
This research compares not only existing hydrological and climatic conditions with predicted hydrological and climatic conditions based on different scenarios, but also the trend of observed hydrological and climatic data with that of predicted hydrological and climatic data. This subject is the most important novelty of this research.

The flowchart of the stages of this research is given in Figure 2.

\section{Results and discussion}

\subsection{Calibration and verification of the extracted precipitation and temperature data from HadCM3 model and SDSM downscaling model}

To predict future precipitation and temperature, relevant data have been extracted from the Canadian Climate Change Scenarios Network (CCCSN) database. The proposed GCM model is HadCM3 model which utilizes scenarios A2 and B2 in this research. To analyze a watershed or a region, the SDSM downscaling model is applied. In HadCM3 model and for precipitation, the most important predictors include relative humidity at $500 \mathrm{hPa}$ (ncepr500af), relative humidity at $850 \mathrm{hPa}$ (ncepr850af), near-surface relative humidity (nceprhumaf), mean temperature at $2 \mathrm{~m}$ (nceptempaf), and $500 \mathrm{hPa}$ geopotential height (ncepp500af). For temperature, the most important predictors are mean sea level pressure (ncepmslpaf), near-surface relative humidity (nceprhumaf), mean temperature at $2 \mathrm{~m}$ (nceptempaf), and $500 \mathrm{hPa}$ geopotential height (ncepp500af).

To evaluate the accuracy of the downscaled data, they are compared with observed data in the base time period (1971-2014). The base time period is divided into two time periods: a time period (19712001) for calibration and a time period (2002-2014) for verification. The values of performance criteria for calibration and verification time periods are given in Table 4.

Table 4 shows that the accuracy of the HadCM3 model and SDSM downscaling model is appropriate; therefore, these models can predict future precipitation and temperature in the Jelogir station. Further, the verification of these models for two scenarios represents which precision of the two scenarios is approximately equal.

\subsection{Prediction of the precipitation and temperature using HadCM3 model and SDSM downscaling model (2030-2073)}

Table 5 shows the average of the predicted values of precipitation depth and temperature for scenarios A2 and B2, 2030-2073, and the mean of observed data, 1971-2014.

Table 5 illustrates that temperature and precipitation will increase and decrease, respectively, in the future. The most seasonal variations are associated with the winter; the highest monthly increasing temperature trend is associated with

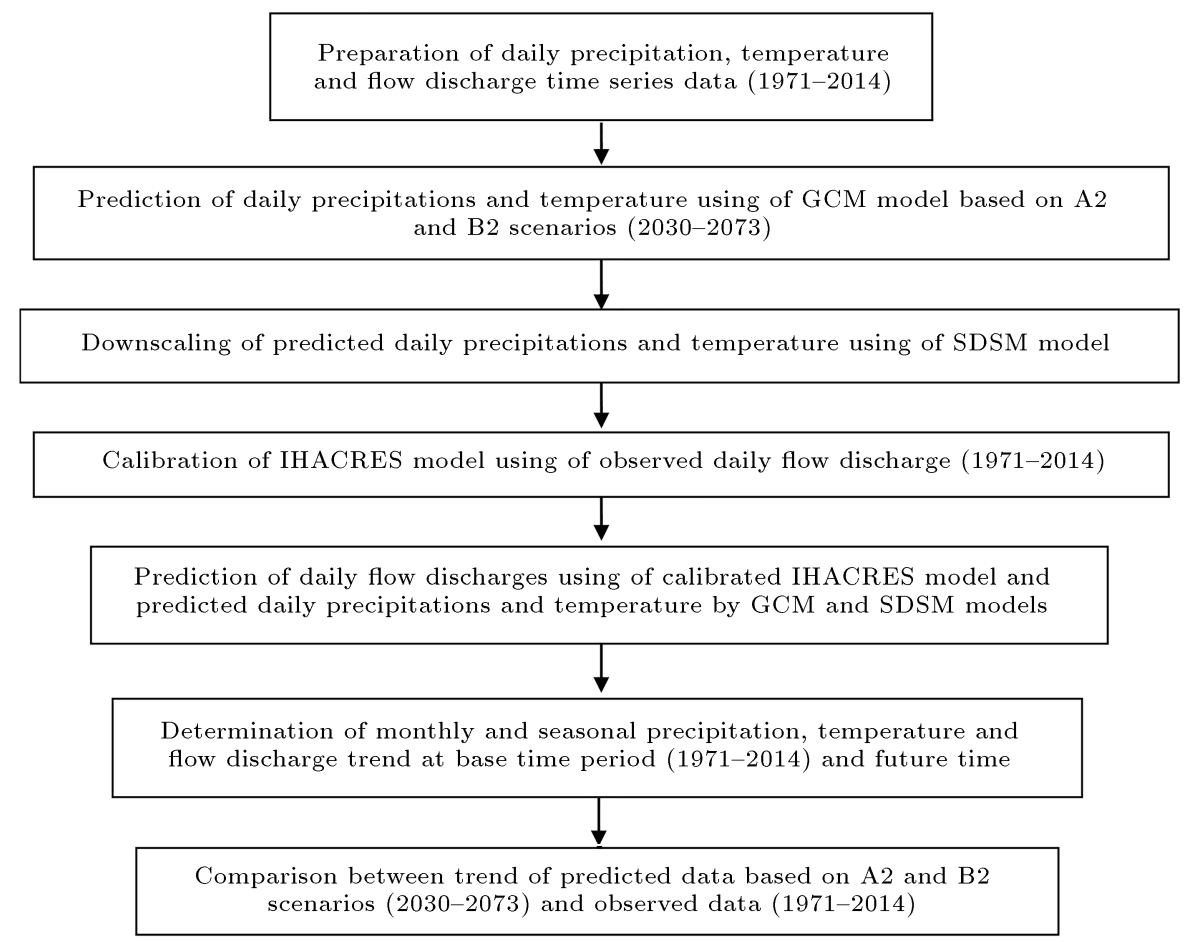

Figure 2. The flowchart of the stages of research. 
Table 4. Root Mean Square Error (RMSE), Normalized Root Mean Square Error (NRMSE), and $\mathrm{R}^{2}$ values of calibration and verification time periods.

\begin{tabular}{ccccc}
\hline Data & $\begin{array}{c}\text { Performance } \\
\text { criteria }\end{array}$ & Calibration & & \multicolumn{2}{c}{ Verification } \\
\cline { 3 - 5 } Precipitation & RMSE $(\mathrm{mm})$ & 0.32 & 0.38 & 0.45 \\
& $\mathrm{NRMSE}$ & 0.1 & 0.102 & 0.12 \\
& $R^{2}$ & 0.947 & 0.976 & 0.953 \\
Temperature & $\mathrm{NRMSE}$ & 0.056 & 0.042 & 0.043 \\
& $\mathrm{RMSE}\left({ }^{\circ} \mathrm{C}\right)$ & 1.68 & 1.29 & 1.29 \\
& $R^{2}$ & 0.977 & 0.993 & 0.991 \\
\hline
\end{tabular}

Table 5. The average of observed and predicted values of precipitation depth and temperature using of scenarios A2 and B2.

\begin{tabular}{|c|c|c|c|c|c|c|}
\hline \multirow[t]{2}{*}{ Month-season } & \multicolumn{3}{|c|}{$\begin{array}{l}\text { Precipitation } \\
\text { depth }(\mathrm{mm})\end{array}$} & \multicolumn{3}{|c|}{$\begin{array}{c}\text { Temperature } \\
\left({ }^{\circ} \mathrm{C}\right)\end{array}$} \\
\hline & Obs & A2 & B2 & Obs & A2 & B2 \\
\hline Jan & 89.64 & 80.04 & 83.47 & 11.51 & 14.92 & 14.85 \\
\hline Feb & 79.78 & 72.22 & 71.35 & 13.71 & 16.77 & 16.8 \\
\hline Mar & 79.52 & 74.66 & 74.21 & 17.98 & 21.3 & 21.78 \\
\hline Apr & 54.03 & 39.64 & 37.06 & 23.95 & 26.23 & 26.27 \\
\hline May & 14.96 & 14.59 & 14.11 & 31.42 & 33.4 & 33.58 \\
\hline Jun & 0.08 & 0 & 0.46 & 38.66 & 40.45 & 39.98 \\
\hline Jul & 0.19 & 0.07 & 0.07 & 41.94 & 43.65 & 43.28 \\
\hline Aug & 0 & 0 & 0 & 41.13 & 42.76 & 42.69 \\
\hline Sep & 1.02 & 2.15 & 2.4 & 36.45 & 37.87 & 37.63 \\
\hline Oct & 16.91 & 22.93 & 22.42 & 28.48 & 30.17 & 29.76 \\
\hline Nov & 61.67 & 58.93 & 60.25 & 19.01 & 20.72 & 20.14 \\
\hline Dec & 90.48 & 78.08 & 78.71 & 13.38 & 16 & 15.89 \\
\hline Winter & 82.98 & 75.64 & 76.34 & 14.4 & 17.66 & 17.81 \\
\hline Spring & 23.02 & 18.08 & 17.21 & 31.35 & 33.36 & 33.28 \\
\hline Summer & 0.4 & 0.74 & 0.83 & 39.84 & 41.43 & 41.2 \\
\hline Autumn & 56.35 & 53.31 & 53.79 & 20.29 & 22.3 & 21.93 \\
\hline
\end{tabular}

January, February, and March; the least monthly increasing temperature trend is associated with September, October, and November. The highest monthly decreasing trend in precipitation is associated with April and December, while the highest monthly increasing trend in precipitation with October.

The annual precipitation depths are 488.28, 443.31 ( $-9.21 \%$ reduction), and 444.51 ( $-8.76 \%$ reduction) $\mathrm{mm}$ for observed data (1971-2014) and predicted precipitation depths using scenarios A2 and B2 (20302073), respectively. Furthermore, the mean annual temperatures are $26.47,28.69^{\circ} \mathrm{C}(8.39 \%$ increase rate), and $28.55^{\circ} \mathrm{C}(7.97 \%$ increase rate $)$ for observed data (1971-2014) and predicted temperatures using scenar- ios A2 and B2 (2030-2073), respectively. In addition, this table presents a lag time of one month between precipitation and temperature, such that the temperature and precipitation reach the highest and lowest in March and April, respectively. From December to April, the increase rate of temperature and the reduction rate of precipitation are more than those in other months because these months experience the highest amount of precipitation and are the coldest months. In scenario A2, the increase rate of temperature and the reduction rate of precipitation are slightly more than those in scenario B2, which places greater emphasis on preserving the environment.

\subsection{Calibration of IHACRES model and prediction of the flow discharge for scenarios $A \mathscr{2}$ and $B 2$}

For the calibration of IHACRES model, daily precipitation depth and temperature in the base time period (1971-2014) were introduced to the model to simulate daily flow discharge. The comparison between observed and simulated flow discharges is given in Figure 3.

The values of the calibrated parameters of IHACRES are given below:

In nonlinear component:

$$
\begin{aligned}
& c=0.000235 \mathrm{~mm}, \quad f=0{ }^{\circ} \mathrm{C}^{-1}, \quad t_{r e f}=20^{\circ} \mathrm{C}, \\
& l=0, \quad p=1, \quad \text { and } \quad \tau_{w}=30^{\circ} \mathrm{C} .
\end{aligned}
$$

In linear component:

$$
\begin{aligned}
& \alpha_{q}=0, \quad \alpha_{s}=-0.751, \quad \beta_{q}=0.013, \\
& \beta_{s}=0.246, \quad \tau_{q}=0 \text { day }, \quad \tau_{s}=3.495 \text { day }, \\
& v_{q}=0.013, \quad v_{s}=0.987 .
\end{aligned}
$$

RMSE, NRMSE, and $R^{2}$ values of the calibrated model, 1971-2014, are 70 CMS, 0.95, and 0.6. Performance criteria show that IHACRES model is a

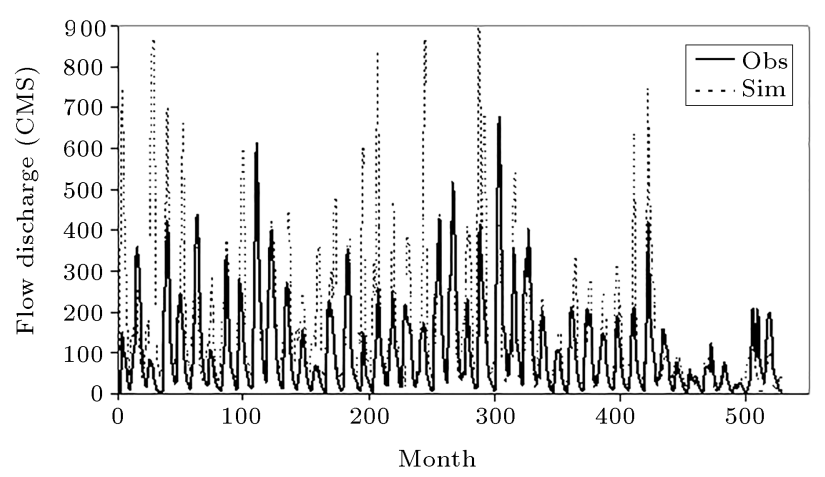

Figure 3. Comparison between observed and simulated flow discharge (1971-2014). 
fairly suitable model, but fails to simulate high flow discharges well because the difference between observed and simulated flow discharges is significant (422 CMS).

In the next step, the predicted precipitation and temperature by HadCM3 model and SDSM downscaling model (2030-2073) were introduced to the calibrated IHACRES model to simulate flow discharge in the future. Table 6 shows the average of predicted values of flow discharge for scenarios A2 and B2, 20302073 , and the mean of observed data, 1971-2014.

Table 6 shows that flow discharge will reduce considerably in the future. In scenario $\mathrm{B} 2$, the reduction of flow discharge is slightly more than that in scenario A2. This table illustrates that the highest seasonal flow discharge reduction is associated with the spring and, also, the highest monthly flow discharge reduction with March, April, and May.

The mean annual flow discharges are 139.18, 78.97 ( $-43.26 \%$ reduction), and 73.96 ( $-46.86 \%$ reduction) CMS for observed data (1971-2014) and predicted flow discharges using scenarios A2 and B2 (2030-2073), respectively. Moreover, this table presents a onemonth lag time between the decreasing trend of flow discharge and the increasing trend of temperature and simultaneously between the reduction of precipitation and flow discharge. From February to May, the decreasing trend of flow discharge is more than that in other months because these months experience the highest flow discharge.

Table 6. The average of observed and predicted values of flow discharge using scenarios A2 and B2.

\begin{tabular}{cccc}
\hline \multirow{2}{*}{ Month-season } & \multicolumn{3}{c}{ Flow discharge (CMS) } \\
\cline { 2 - 4 } & Obs & A2 & B2 \\
\hline Jan & 139.45 & 129.85 & 121.77 \\
Feb & 209.02 & 146.24 & 140.23 \\
Mar & 335.9 & 147.69 & 142.56 \\
Apr & 327.89 & 119.96 & 115.19 \\
May & 188.46 & 81.55 & 78.27 \\
Jun & 75.85 & 52.43 & 50.5 \\
Jul & 44.42 & 33.61 & 32.39 \\
Aug & 34.62 & 21.54 & 20.76 \\
Sep & 34.16 & 17.6 & 17.14 \\
Oct & 51.11 & 29.61 & 28 \\
Nov & 97.34 & 64.05 & 53.1 \\
Dec & 131.95 & 103.48 & 87.57 \\
Winter & 228.12 & 141.26 & 134.85 \\
Spring & 197.4 & 84.65 & 81.32 \\
Summer & 37.73 & 24.25 & 23.43 \\
Autumn & 93.46 & 65.71 & 56.23 \\
\hline
\end{tabular}

\subsection{Determination of the trend of observed and predicted meteorological and hydrometric phenomena using MK test and TSA estimator}

The observed data from 1971 to 2014 is as follows. According to the MK test and TSA estimator, the precipitation time series data point to a decreasing trend from December to March and an increasing trend in April, May, October, and November. Significance level is $99 \%$ in March and $90 \%$ in October. March and November experience maximum reduction ( $-18.07 \mathrm{~mm} /$ decade) and maximum increase (1.67 mm/decade), respectively.

Temperature time series data show a decreasing trend from September to December and an increasing trend from January to August. The significance level is $95 \%$ in the cases of March, June, and November and $90 \%$ in the case of May. November and March experienced maximum reduction $\left(-0.47^{\circ} \mathrm{C} /\right.$ decade $)$ and maximum increase $\left(0.45^{\circ} \mathrm{C} /\right.$ decade $)$, respectively.

Flow discharge time series data show a decreasing trend and a significance level of $99 \%$ in all months. March experienced maximum reduction (97.87 CMS/decade).

The predicted data for scenario A2 (2030-2073) is as follows. The predicted precipitation time series data in scenario A2 show a decreasing trend from September to February, April, and May and an increasing trend in March. The significance level is $90 \%$ in the cases of January and October. January and March experienced maximum reduction $(-3.41 \mathrm{~mm} /$ decade $)$ and maximum increase $(0.22 \mathrm{~mm} /$ decade $)$, respectively.

The predicted temperature time series data in scenario A2 exhibit an increasing trend in all months. The significance level is $90 \%$ in June, $95 \%$ in October and December, and 99\% from January, February, and July to September. October experienced maximum increase $\left(0.76^{\circ} \mathrm{C} /\right.$ decade $)$.

The predicted flow discharge time series data in scenario A2 show the decreasing trend from February to September and the increasing trend from October to January. April and November experience maximum reduction (-3.04 CMS/decade) and maximum increase (6.15 CMS/decade).

The predicted data for scenario B2 (2030-2073) is as follows. The predicted precipitation time series data in scenario B2 show the decreasing trend from October to February and the increasing trend from March to May and September. The significance level is $90 \%$ in October. October and April experience maximum reduction $(-2.66 \mathrm{~mm} /$ decade $)$ and maximum increase (1.17 mm/decade), respectively.

The predicted temperature time series data in scenario B2 show the increasing trend from June to January and March and the decreasing trend from February, April, and May. Significance level is $90 \%$ 
in January and August, 95\% in September and October, and $99 \%$ in July. October and May experience maximum increasing $\left(0.78^{\circ} \mathrm{C} /\right.$ decade $)$ and maximum reduction $\left(-0.32^{\circ} \mathrm{C} /\right.$ decade $)$, respectively.

The predicted flow discharge time series by scenario B2 show a decreasing trend from February to August and an increasing trend from September to January. April and November experience maximum reduction (-2.64 CMS/decade) and maximum increase (4.19 CMS/decade), respectively.

\subsubsection{The annual precipitation, mean of annual temperatures, and flow discharge}

Observed data (1971-2014) is as follows. The annual precipitation experiences a decreasing trend $(-40.71 \mathrm{~mm} /$ decade) with a significance level of $95 \%$. The mean of annual temperature experiences an increasing trend $\left(0.09^{\circ} \mathrm{C} /\right.$ decade $)$. The mean of annual flow discharge has a decreasing trend (-36.53 CMS/decade) at a significance level of $99 \%$;

The predicted data for scenario A2 (2030-2073) is as follows. The annual precipitation has a decreasing trend $(-11.13 \mathrm{~mm} /$ decade $)$. The mean of annual temperature shows an increasing trend $\left(0.47^{\circ} \mathrm{C} /\right.$ decade $)$ at a significance level of $99 \%$. The mean of annual flow discharge has an increasing trend (3.14 CMS/decade);

The predicted data for scenario B2 (2030-2073) is as follows. The annual precipitation has a decreasing trend $(-6.12 \mathrm{~mm} /$ decade $)$. The mean of annual temperature has an increasing trend $\left(0.18^{\circ} \mathrm{C} /\right.$ decade). The mean of annual flow discharge has a decreasing trend (-0.17 CMS/decade).

MK trend test and TSA estimator show that the decreasing trend of flow discharge and precipitation will slow down, while the increasing trend of temperature accelerates in the future. The production of greenhouse gases and the increasing rate of temperature in scenario $\mathrm{A} 2$ are more than those in scenario B2. This will increase the snow-melting rate, i.e., the main source of water supply in the Karkheh River; therefore, the trend of flow discharge is incremental in scenario A2. Moreover, the decreasing rate of precipitation in scenario A2 is higher than that in scenario B2.

\section{Conclusion}

This research showed that the amount of precipitation and flow discharge would reduce and the temperature would increase in the future. The application of different scenarios, A2 and B2, proved this finding, the results of which demonstrated the negligible difference between applications of these scenarios in the time period of 2030-2073. However, in the long term, the difference between results of the scenarios becomes clear (based on results of Mann Kendal (MK) test and Theil-Sen Approach (TSA) estimator). Scenario B2 places greater emphasis on preserving the environment. This scenario showed a lower incremental rate of temperature and a reduced rate of precipitation than scenario A2. In scenario A2, a higher incremental rate of temperature increased the snow-melting rate in mountainous areas and increased flow discharge. MK test and TSA estimator illustrated that trend lines of observed data in the base time period (1971-2014) had very steep slopes, which will be adjusted in the future.

Although the rise of temperature accelerates evaporation from the reservoir of the Karkheh Dam, it cannot increase precipitation in the Jelogir hydrometric station. The Jelogir station height is relatively low $(385 \mathrm{~m})$; therefore, vapor from the reservoir of the Karkheh Dam must be transferred to higher regions to ensure rainfall.

In addition, this research considered a one-month lag time between temperature and precipitation variations and, also, precipitation and flow discharge variations. In the winter and spring, the changes of meteorological and hydrological data are more significant than that in other seasons. The reduction of precipitation and increase of temperature are intense from December to April. Most of the flow discharge changes are associated with February to May.

The results of this study are in good agreement with those of other studies in Iran. These studies illustrate the increasing temperature and the decreasing flow discharge and precipitation in different regions of Iran. For example, the studies by Adib et al. [15], Somee et al. [16], Tabari et al. [17], Abghari et al. [18], Khalili et al. [19], and Zamani et al. [20] are worthy of closer consideration.

The developed procedure for this research proves the destructive effects of global warming on meteorological and hydrological changes of the Karkheh River in southwest of Iran. The rising temperature and reduced precipitation and flow discharge are significant factors that managers, governing authorities, and NonGoverning Organizations (NGOs) must consider in the future water resources planning. For example, in the case of transferring water from southwest of Iran to the central region of the country, the Iranian government must take the effects of global warming into account and make correct decisions.

\section{References}

1. Mann, H.B. "Nonparametric tests against trend", Econometrica, 13(3), pp. 245-259 (1945).

2. Kendall, M.G., Rank Correlation Methods, 4th Ed., Charles Griffin, London (1975).

3. Theil, H. "A rank invariant method for linear and polynomial regression analysis", Nederl. Akad. Wetensch. Proc. Ser. A, 53, 386-392 (Part I), 521-525 (Part II), 1397-1412 (Part III) (1950). 
4. Sen, P.K. "Estimates of the regression coefficient based on Kendall's tau", J. Am. Stat. Assoc., 63(324), pp. 1379-1389 (1968).

5. Yue, S., Pilon, P., Phinney, B., and Cavadias, G. "The influence of autocorrelation on the ability to detect trend in hydrological series", Hydrol. Process, 16(9), pp. 1807-1829 (2002).

6. Taxak, A.K., Murumkar, A.R., and Arya, D.S. "Long term spatial and temporal rainfall trends and homogeneity analysis in Wainganga basin, Central India", Weather Clim. Extremes, 4, pp. 50-61 (2014).

7. Kumar, V. and Jain, S.K. "Trends in rainfall amount and number of rainy days in river basins of India (19512004)", Hydrol. Res., 42(4), pp. 290-306 (2011).

8. Subash, N., Singh, S.S., and Priya, N. "Variability of rainfall and effective onset and length of the monsoon season over a sub-humid climatic environment", Atmos. Res., 99(3-4), pp. 479-487 (2011).

9. Sayemuzzaman, M. and Jha, M.K. "Seasonal and annual precipitation time series trend analysis in North Carolina, United States", Atmos. Res., 137, pp. 183194 (2014).

10. Tekleab, S., Mohamed, Y., and Uhlenbrook, S. "Hydro-climatic trends in the Abay/Upper Blue Nile basin, Ethiopia", Phys. Chem. Earth Pts. A/B/C, 6162, pp. 32-42 (2013).

11. Addisu, S., Selassie, Y.G., Fissha, G., and Gedif, B. "Time series trend analysis of temperature and rainfall in lake Tana Sub-basin, Ethiopia", Environ. Syst. Res., 4(1), p. 25 (2015).

12. Beyene, A.N. "Precipitation and temperature trend analysis in Mekelle city, Northern Ethiopia, the case of Illala meteorological station", J. Earth Sci. Climatic Change, 7(1), p. 324 (2016).

13. Croitoru, A.E., Piticar, A., Dragotă, C.S., and Burada, D.C. "Recent changes in reference evapotranspiration in Romania", Global Planet. Change, 111, pp. 127-136 (2013).

14. De la Casa, A.C. and Nasello, O.B. "Low frequency oscillation of rainfall in Córdoba, Argentina, and its relation with solar cycles and cosmic rays", Atmos. Res., 113, pp. 140-146 (2012).

15. Adib, A., Kalaee, M.M.K., Shoushtari, M.M., and Khalili, K. "Using of gene expression programming and climatic data for forecasting flow discharge by considering trend, normality, and stationarity analysis", Arab. J. Geosci., 10(9), Article 208 (2017).

16. Somee, B.S., Ezani, A., and Tabari, H. "Spatiotemporal trends and change point of precipitation in Iran", Atmos. Res., 113, pp. 1-12 (2012).

17. Tabari, H., Somee, B.S., and Zadeh, M.R. "Testing for long-term trends in climatic variables in Iran", Atmos. Res., 100(1), pp. 132-140 (2011).

18. Abghari, H., Tabari, H., and Talaee, P.H. "River flow trends in the west of Iran during the past 40 years: impact of precipitation variability", Global Planet. Change, 101, pp. 52-60 (2013).
19. Khalili, K., Tahoudi, M.N., Mirabbasi, R., and Ahmadi, F. "Investigation of spatial and temporal variability of precipitation in Iran over the last half century", Stoch. Env. Res. Risk A., 30(4), pp. 12051221 (2016).

20. Zamani, R., Mirabbasi, R., Abdollahi, S., and Jhajharia, D. "Streamflow trend analysis by considering autocorrelation structure, long term persistence, and Hurst coefficient in a semi-arid region of Iran", Theor. Appl. Climatol., 129(1-2), pp. 33-45 (2017).

21. Ay, M. and Kişi, Ö. "Investigation of trend analysis of monthly total precipitation by an innovative method", Theor. Appl. Climatol, 120(3-4), pp. 617-629 (2015).

22. Xu, K., Milliman, J.D., and Xu, H. "Temporal trend of precipitation and runoff in major Chinese rivers since 1951", Global Planet. Change, 73(3-4), pp. 219-232 (2010).

23. Caloiero, T. "Trend of monthly temperature and daily extreme temperature during 1951-2012 in New Zealand", Theor. Appl. Climatol., 129(1-2), pp. 111127 (2017).

24. Wang, H. and Lau, K.M. "Atmospheric hydrological cycle in the tropics in twentieth century coupled climate simulations", Int. J. Climatol., 26(5), pp. 655678 (2006).

25. DeGaetano, A.T. and Castellano, C.M. "Future projections of extreme precipitation intensity-durationfrequency curves for climate adaptation planning in New York State", Climate Serv., 5, pp. 23-35 (2017).

26. Hashmi, M.Z., Shamseldin, A.Y., and Melville, B.W. "Comparison of SDSM and LARS-WG for simulation and downscaling of extreme precipitation events in a watershed", Stoch. Env. Res. Risk A., 25(4), pp. 475484 (2011).

27. Gulacha, M.M. and Mulungu, D.M.M. "Generation of climate change scenarios for precipitation and temperature at local scales using SDSM in Wami-Ruvu River Basin Tanzania", Phys. Chem. Earth Pts. A/B/C, 100, pp. 62-72 (2017).

28. Lima, C.H.R., Kwon, H.H., and Kim, J.Y. "A Bayesian beta distribution model for estimating rainfall IDF curves in a changing climate", J. Hydrol., 540, pp. 744-756 (2016).

29. Agilan, V. and Umamahesh, N.V. "Is the covariate based non-stationary rainfall IDF curve capable of encompassing future rainfall changes?", J. Hydrol., 541(Part B), pp. 1441-1455 (2016).

30. Mailhot, A., Duchesne, S., Caya, D., and Talbot, G. "Assessment of future change in intensity-durationfrequency (IDF) curves for Southern Quebec using the Canadian Regional Climate Model (CRCM)", J. Hydrol., 347(1-2), pp. 197-210 (2007).

31. Alam, M.S. and Elshorbagy, A. "Quantification of the climate change-induced variations in intensityduration-frequency curves in the Canadian Prairies", J. Hydrol., 527, pp. 990-1005 (2015). 
32. Simonovic, S.P., Schardong, A., Sandink, D., and Srivastav, R. "A web-based tool for the development of intensity duration frequency curves under changing climate", Environ. Modell. Softw., 81, pp. 136-153 (2016).

33. Khan, M.S., Coulibaly, P., and Dibike, Y. "Uncertainty analysis of statistical downscaling methods", J. Hydrol., 319(1-4), pp. 357-382 (2006).

34. Kuo, C.C., Gan, T.Y., and Hanrahan, J.L. "Precipitation frequency analysis based on regional climate simulations in Central Alberta", J. Hydrol, 510, pp. 436-446 (2014).

35. Pour, S.H., Shahid, S., Chung, E.S., and Wang, X.J. "Model output statistics downscaling using support vector machine for the projection of spatial and temporal changes in rainfall of Bangladesh", Atmos. Res., 213, pp. 149-162 (2018).

36. Sehgal, V., Lakhanpal, A., Maheswaran, R., Khosa, R., and Sridhar, V. "Application of multi-scale wavelet entropy and multi-resolution Volterra models for climatic downscaling", J. Hydrol., 556, pp. 1078-1095 (2018).

37. Hertig, E. and Tramblay, Y. "Regional downscaling of Mediterranean droughts under past and future climatic conditions", Global Planet. Change, 151, pp. 36-48 (2017).

38. Osman, Y.Z. and Abdellatif, M.E. "Improving accuracy of downscaling rainfall by combining predictions of different statistical downscale models", Water Sci., 30(2), pp. 61-75 (2016).

39. Sinha, P., Mann, M.E., Fuentes, J.D., Mejia, A., Ning, L., Sun, W., He, T., and Obeysekera, J. "Downscaled rainfall projections in south Florida using self-organizing maps", Sci. Total Environ., 635, pp. 1110-1123 (2018).

40. Sachindra, D.A., Ahmed, K., Rashid, M.M., Shahid, S., and Perera, B.J.C. "Statistical downscaling of precipitation using machine learning techniques", Atmos. Res., 212, pp. 240-258 (2018).

41. Sa'adi, Z., Shahid, S., Chung, E.S., and Ismail. T.B. "Projection of spatial and temporal changes of rainfall in Sarawak of Borneo Island using statistical downscaling of CMIP5 models", Atmos. Res., 197, pp. 446-460 (2017).

42. Pour, S.H., Shahid, S., and Chung, E.S. "A hybrid model for statistical downscaling of daily rainfall", Procedia Eng., 154, pp. 1424-1430 (2016).

43. Adib, A. and Gafari Rad, S. "Development of a new integrated method for generation IDF curves based on three climatic changes scenarios", Sci. Iran., 26(2), pp. 742-751 (2019).

44. Sahraei, S., Zare Andalani, S., Zakermoshfegh, M., Nikeghbal Sisakht, B., Talebbeydokhti, N., and Moradkhani, H. "Daily discharge forecasting using least square support vector regression and regression tree", Sci. Iran., 22(2), pp. 410-422 (2015).
45. Chitsaz, N. and Hosseini-Moghari, S.M. "Introduction of new datasets of drought indices based on multivariate methods in semi-arid regions", Hydrol. Res., 49(1), pp. 266-280 (2018).

46. Gordon, C., Cooper, C., Senior, C.A., Banks, H., Gregory, J.M., Johns, T.C., Mitchell, J.F.B., and Wood, R.A. "The simulation of SST, sea ice extents and ocean heat transports in a version of the Hadley Centre coupled model without flux adjustments", Clim. Dynam., 16(2-3), pp. 147-168 (2000).

47. Pope, V.D., Gallani, M.L., Rowntree, P.R., and Stratton, R.A. "The impact of new physical parameterizations in the Hadley Centre climate model: HadAM3", Clim. Dynam., 16(2-3), pp. 123-146 (2000).

48. Collins, M., Tett, S.F.B., and Cooper, C. "The internal climate variability of HadCM3, a version of the Hadley Centre coupled model without flux adjustments", Clim. Dynam., 17(1), pp. 61-81 (2001).

49. "Summary for policymakers-emissions scenarios", A special report of working group III of the intergovernmental panel on climate change, World Meteorological Organization (WMO) (2000).

50. Jakeman, A.J., Littlewood, I.G., and Whitehead, P.G. "Computation of the instantaneous unit hydrograph and identifiable component flows with application to two small upland catchments", J. Hydrol., 117(1-4), pp. 275-300 (1990).

51. Pettitt, A.N. "A non-parametric approach to the change-point problem", J. Roy. Stat. Soc. C-App., 28(2), pp. 126-135 (1979).

\section{Biographies}

Arash Adib is a Professor at the Civil Engineering Department, Engineering Faculty, Shahid Chamran University, Ahvaz, Iran. He has almost 60 journal papers and 120 conference papers. He accomplished 3 research projects for water and energy ministry of Iran (Khuzestan Water and Power Authority). He received a scholarship from British Council in 2004 and became reputable Iranian superior researcher medal in December 2012. He has been a supervisor to almost 50 MSc theses and $6 \mathrm{PhD}$ theses.

Seyyedeh Batol Mirsalari is a Water Resources Engineering Student at the Civil Engineering Department, Engineering Faculty, Shahid Chamran University, Ahvaz, Iran. Her supervisor was Arash Adib. She obtained her MSc degree in February 2018 and has presented two conference papers so far.

Seyed Mohammad Ashrafi is an Assistant Professor at the Civil Engineering Department, Engineering Faculty, Shahid Chamran University, Ahvaz, Iran. He has almost 5 journal papers and 20 conference papers. He has been a supervisor to almost 5 MSc theses. 